\title{
BIDIRECTIONAL CAVOPULMONARY SHUNT WITH RIGHT VENTRICULAR OUTFLOW PATENCY: THE IMPACT OF PULSATILITY ON PULMONARY ENDOTHELIAL FUNCTION
}

\author{
Shunji Kurotobi, MD \\ Tetsuya Sano, MD \\ Shigetoyo Kogaki, MD \\ Tohru Matsushita, MD \\ Takashi Miwatani, MD \\ Makoto Takeuchi, MD \\ Hikaru Matsuda, MD \\ Shintaro Okada, MD
}

\begin{abstract}
Objective: Although in vitro studies have suggested the importance of flow pulsatility in endothelial function, few reports have focused on pulmonary endothelial function under decreased pulsatile flow after a bidirectional cavopulmonary shunt with or without an additional pulmonary flow source. The purpose of the present study was to assess the pulmonary endothelial function after bidirectional cavopulmonary shunt.
\end{abstract}

Methods and results: Pulmonary vasodilating response was evaluated in 10 patients 0.4 to 7.0 years (median 1.6 years) after bidirectional cavopulmonary shunt who were provided an additional flow source by retaining the pulmonary outflow tract and in 8 control subjects. Average pulmonary flow velocity was measured with a Doppler flow wire placed in the segmental lower lobe pulmonary artery during incremental infusion of acetylcholine $\left(10^{-8}, 10^{-7}, 10^{-6}\right.$, and $\left.10^{-5} \mathrm{~mol} / \mathrm{L}\right)$ and then of nitroglycerin $(0.5$ and $1.0 \mu \mathrm{g}$. $\left.\mathrm{kg}^{-1} \cdot \mathrm{min}^{-1}\right)$ after recovery. In the control subjects, a dose-dependent increase in flow velocity was observed in response to acetylcholine (maximum increase was $155 \% \pm 17 \%$ of baseline) and to nitroglycerin (maximum increase was $151 \% \pm 20 \%$ of baseline). In contrast, patients showed a significantly impaired response to acetylcholine (maximum increase was $124 \%$ $\pm 17 \%$ of baseline; $P<.01 \mathrm{vs}$ control), whereas the response to nitroglycerin was preserved $(138 \% \pm 12 \%$ of baseline; $P=.09$ vs control). In addition, the maximum response to acetylcholine correlated significantly with the pulmonary pulse pressure $(r=0.89, P<.01)$ and with the pulmonary flow pulsatility $(r=0.88, P<.01)$.

Conclusions: These results clearly suggest that patients after bidirectional cavopulmonary shunt show pulmonary endothelial functional attenuation and, of more importance, that decreased pulsatility of cavopulmonary flow is mainly responsible for this endothelial abnormality. ( $\mathrm{J}$ Thorac Cardiovasc Surg 2001;121:1161-8)

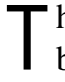
he bidirectional cavopulmonary shunt (BCPS), or bidirectional Glenn shunt, has frequently been performed as a primary palliation or intermediate step before the ultimate Fontan-type repair in patients with univentricular heart syndrome. ${ }^{1-4}$ However, several disadvantages regarding nonpulsatile or decreased pulsatile pulmonary flow after the BCPS have been reported, as well as the importance of flow pulsatility in both global and microvascular pulmonary circulation.

From the Department of Pediatrics and First Department of Surgery, Osaka University, Osaka, Japan.

Copyright () 2001 by The American Association for Thoracic Surgery

0022-5223/2001 $\$ 35.00+0 \quad \mathbf{1 2 / 1 / 1 1 3 0 2 4}$

doi: $10.1067 / \mathrm{mtc} .2001 .113024$
Previous experimental studies have shown pulmonary vascular resistance to be significantly elevated ${ }^{5,6}$ and lung water content to be increased ${ }^{5}$ with nonpulsatile pulmonary flow. Few reports, however, confirm sequelae caused by nonpulsatile pulmonary flow in the clinical setting, that is, in patients after BCPS.

The present study was designed to elucidate the importance of pulsatility of pulmonary arterial flow and identify its relation to pulmonary vascular dysfunction after BCPS. The purpose of this study was to evaluate whether differences in pulsatile flow would be associated with alterations in endothelial nitric oxide (NO) production. In this study we assessed the impact of pulsatile flow on pulmonary endothelial function using acetylcholine $(\mathrm{ACH})$, an endothelium-dependent vasodilator, and compared the effect of $\mathrm{ACH}$ with that 
Table I. Cardiac diagnosis in the study population

\begin{tabular}{|c|c|c|c|}
\hline Case (sex, age $[y]$ ) & Diagnosis & Previous surgery & Medication \\
\hline \multicolumn{4}{|l|}{ Patients with BCPS } \\
\hline $1(\mathrm{~F}, 4.2)$ & DIRV, PS, TAPVC, D-TGA & BT shunt & $\mathrm{D}, \mathrm{F}, \mathrm{S}$ \\
\hline $2(\mathrm{M}, 3.9)$ & DIRV, PS, TAPVC, D-TGA & BT shunt & $\mathrm{D}, \mathrm{F}, \mathrm{S}$ \\
\hline $3(\mathrm{M}, 17.0)$ & DIRV, PS, TAPVC, D-TGA & BT shunt & $\mathrm{D}, \mathrm{F}, \mathrm{S}$ \\
\hline $4(\mathrm{M}, 5.3)$ & DIRV, PS, TAPVC, D-TGA & BT shunt & $\mathrm{D}, \mathrm{F}, \mathrm{S}$ \\
\hline $5(\mathrm{M}, 5.5)$ & DIRV, PS, TAPVC, D-TGA & BT shunt & None \\
\hline $6(\mathrm{~F}, 5.3)$ & DIRV, PS, TAPVC, D-TGA & BT shunt & None \\
\hline $7(\mathrm{~F}, 12.0)$ & MA, PS, D-TGA & BT shunt & None \\
\hline $8(\mathrm{M}, 5.5)$ & $\mathrm{PA} / \mathrm{IVS}$ & BT shunt, RVOTR & None \\
\hline $9(\mathrm{M}, 3.0)$ & TA, PS, D-TGA & BT shunt & None \\
\hline $10(\mathrm{M}, 5.0)$ & corrected TGA, hypoplastic LV & BT shunt & None \\
\hline \multicolumn{4}{|l|}{ Control subjects } \\
\hline $1(\mathrm{M}, 3.0)$ & $\mathrm{CoA}$ & None & None \\
\hline $2(\mathrm{M}, 3.0)$ & $\mathrm{CoA}$ & None & None \\
\hline $3(\mathrm{M}, 11.2)$ & $\mathrm{CoA}$ & None & None \\
\hline $4(\mathrm{M}, 8.0)$ & $\mathrm{CoA}$ & None & None \\
\hline $5(\mathrm{M}, 3.1)$ & $\mathrm{CoA}$ & Repair & None \\
\hline $6(\mathrm{M}, 3.1)$ & $\mathrm{CoA}$ & Repair & None \\
\hline $7(\mathrm{~F}, 3.2)$ & AS & None & None \\
\hline $8(\mathrm{M}, 10.6)$ & Ebstein & None & None \\
\hline
\end{tabular}

$D I R V$, Double-inlet right ventricle; $P S$, pulmonary stenosis; TAPVC, total anomalous pulmonary venous connection; $D$-TGA, dextro-transposition of great arteries; $P A / I V S$, pulmonary atresia with intact ventricular septum; $M A$, mitral atresia; $T A$, tricuspid atresia; $C o A$, coarctation of the aorta; $A S$, aortic stenosis; $B T$, BlalockTaussig; RVOTR, right ventricular outflow tract reconstruction; $D$, digoxin; $F$, furosemide; $S$, spironolactone.

of nitroglycerin (NTG), an endothelium-nondependent vasodilator and exogenous $\mathrm{NO}$ donor.

\section{Methods}

Study population. Between January 1996 and September 1997, we studied pulmonary arterial hemodynamics after BCPS in 10 patients ( 7 boys and 3 girls) 3 to 17 years old (median 5.3 years) who were provided additional flow through patent pulmonary ventricular outflow. All 10 of these patients underwent cardiac catheterization to determine surgical indications for Fontan completion and post-BCPS hemodynamic evaluation. The cardiac diagnoses previously confirmed by cross-sectional echocardiogram, cineangiogram, and/or surgical findings are outlined in Table I. The interval between the BCPS procedure and catheterization ranged from 0.4 to 7.0 years (median 1.6 years). With respect to previous operations, all patients had undergone BlalockTaussig shunt elimination at BCPS creation. No abnormal pulmonary venous physiologic condition was demonstrated by echocardiography and catheterization. Four patients were being treated preventively with low doses of furosemide, digoxin, and/or spironolactone, although they had no clinical sign of congestive heart failure.

We selected 8 patients with normal pulmonary hemodynamics as control subjects ( $6 \pm 4$ years). The group consisted of 4 patients with mild simple coarctation of the aorta, 1 with mild aortic stenosis, 1 with mild tricuspid regurgitation, and 2 patients who had undergone repair of coarctation of the aorta without any residua.

No participant had parenchymal lung disease or any chro- mosomal or extracardiac abnormality. Written informed consent was obtained from all participants or their parents.

Study protocol. All medications were discontinued at least 12 hours before the study. All subjects underwent diagnostic catheterization first under mild sedation (pethidine hydrochloride) with local anesthesia via the internal jugular and femoral approach. After the pressure and oxygen measurements, diazepam $(0.2-0.3 \mathrm{mg} / \mathrm{kg})$ was administered intravenously before the study began. The studies were performed before angiography. According to body size, a $5 \mathrm{~F}$ or $6 \mathrm{~F}$ wedge catheter was inserted into the medial or posterior branch of the lower lobe pulmonary artery through the internal jugular vein. A Doppler flow wire (Cardiometrics, Mountain View, Calif), a 175-cm long, 0.014-inch diameter steerable guidewire with a 12-MHz transducer at its distal tip, was positioned through the end-hole catheter into a straight segment of the lower lobe pulmonary artery. Doppler velocity signals were processed with on-line fast Fourier transform by a real-time spectrum analyzer. The Doppler signal was displayed as a continuous spectral velocity envelope and was recorded onto VHS tape.

After the stability of the Doppler wire and flow signals had been confirmed, control glucose and vasoactive agents were infused serially at a maintained rate of $100 \mathrm{~mL} / \mathrm{min}$ via the wedge catheter into the segmental pulmonary artery. Doppler flow signals were obtained during a 3-minute control infusion (5\% glucose) and every 3 minutes during incremental infusion of ACH $10^{-8}, 10^{-7}$, and $10^{-6} \mathrm{~mol} / \mathrm{L}$ in the presence of $5 \%$ glucose. In 4 of the patients who had BCPS, Doppler flow measurements were taken during an additional infusion of $\mathrm{ACH}, 10^{-5} \mathrm{~mol} / \mathrm{L}$, inducing the maximum response to $\mathrm{ACH}$. 


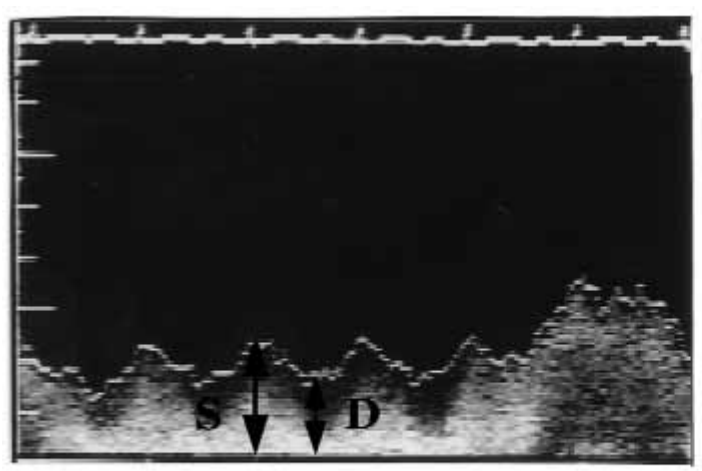

BCPS

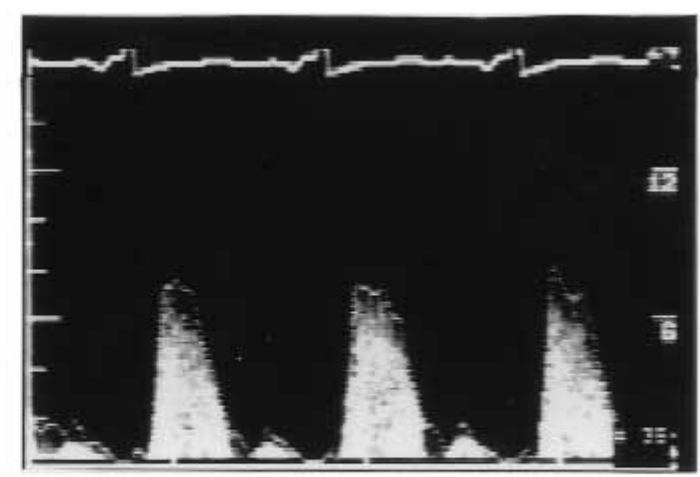

Control

Fig 1. Spectral Doppler flow velocity in the pulmonary artery. In BCPS, less pulsatile flow with inspiratory augmentation is demonstrated. The pulsatility is calculated as peak systolic flow velocity $(S)$ divided by diastolic nadir velocity $(D)$ and averaged over 30 seconds before the end of the glucose infusion.

After a 4-minute recovery of control infusion, Doppler measurements were repeated during NTG infusions with doses of 0.5 and $1.0 \mu \mathrm{g} \cdot \mathrm{kg}^{-1} \cdot \mathrm{min}^{-1}$ for 3 minutes each. The mean flow velocity (in centimeters per second) was calculated and averaged for the last 30 seconds of each infusion period.

Pulmonary artery branch angiography was then performed through the catheter to measure the vessel diameter. The measurements were calibrated to the known external diameter of the non-contrast-filled guiding catheter.

Pulsatility of the pulmonary artery flow was assessed by the pulmonary pulse pressure and pulsatility index (PI). The pulmonary pulse pressure was defined as the pressure difference, which was calculated as systolic peak pressure subtracted from the diastolic pressure nadir, and the PI was calculated as peak systolic flow velocity divided by the diastolic velocity nadir (Fig 1). Both indicators of the pulmonary flow pulsatility were averaged for the 30 seconds before the end of the control glucose infusion.

Statistics. Data are expressed as mean \pm SD. Results of the mean flow velocity for each infusion are expressed as the percentage relative to the control value obtained during control glucose infusion for each subject. Therefore, the paired $t$ test was used to assess the changes observed in flow velocity. Comparisons between the 2 groups, the BCPS and control groups, were performed by means of the unpaired $t$ test. Linear regression analysis was used to correlate PI and the percent increase of the mean flow velocity.

\section{Results}

Basal hemodynamic profiles of each subject are shown in Table II. There were no significant differences in these hemodynamic parameters between the 2 groups except in pulmonary pulse pressure and in systemic arterial oxygen saturation. The pulmonary pulse pressure in the BCPS group (mean $4 \mathrm{~mm} \mathrm{Hg}$ ) was sig- nificantly lower than that in the control group (mean 18 $\mathrm{mm} \mathrm{Hg} ; P<.01$ ), even with the additional flow. Pulmonary pulse pressure in patients who had BCPS varied widely from $1 \mathrm{~mm} \mathrm{Hg}$ to $10 \mathrm{~mm} \mathrm{Hg}$. Systemic oxygen saturation in the BCPS group was also significantly lower than that in the control group $(P<.01)$. There were no significant changes in systemic pressure and heart rate monitoring during the infusion of $\mathrm{ACH}$ or NTG, despite a $5 \%$ increase in heart rate and an $8 \%$ decrease in systemic pressure during NTG infusion, and pulmonary pressure little changed. The vessel diameter at the Doppler flow measurement was $3.5 \pm$ $0.4 \mathrm{~mm}$ in the BCPS group and $3.2 \pm 0.2 \mathrm{~mm}$ in the control group, showing no significant difference.

Basal pulmonary flow pattern. The characteristic biphasic pulmonary flow pattern with continuous forward flow was observed in all patients after BCPS. The flow was increased on electrocardiograms during both ventricular and atrial systole. During inspiration, a considerable augmentation of forward flow was noted. Control subjects, however, had a biphasic pulsatile pulmonary flow pattern with less basic continuous flow, which was only slightly augmented during inspiration (Fig 1).

The response of flow velocity to $\mathrm{ACH}$ and NTG. In response to both ACH and NTG, a dose-dependent increase in mean flow velocity was demonstrated in both the BCPS and control groups. However, the percent response to $\mathrm{ACH}$ was lower in the BCPS group than in the control group, and the maximum percent response in the BCPS group was significantly lower than in the control group $(124 \% \pm 17 \%$ vs $155 \% \pm$ $17 \% ; P<.01)$. The maximum percent increase in 

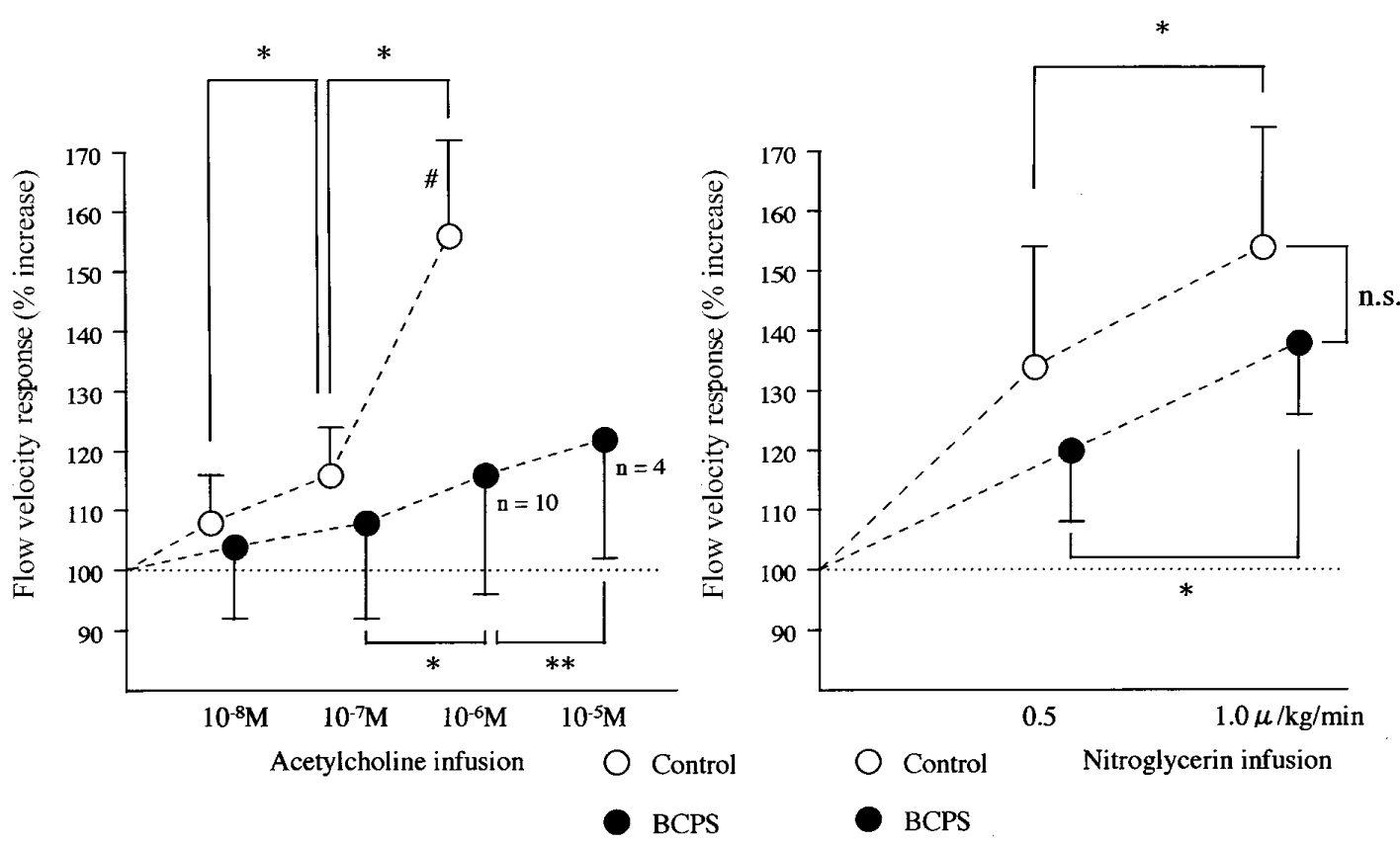

Fig 2. Changes in the mean flow velocity in the pulmonary artery. Left, Response to ACH; right, response to NTG; n.s., not significant. A dose-dependent increase in flow velocity occurred in response to both ACH and NTG infusion $(* P<.01, * * P<.05)$. In response to $\mathrm{ACH}$, maximal increase in the flow velocity is significantly lower in patients with BCPS than in control subjects $(\# P<.01)$. In response to NTG, there is no significant difference between the 2 groups.

Table II. Basal hemodynamic profile in each study group

\begin{tabular}{lccc}
\hline & BCPS group & Control group & P value \\
\hline Mean PAP (mm Hg) & $14 \pm 5$ & $17 \pm 3$ & NS \\
Pulmonary pulse pressure (mm Hg) & $4 \pm 3$ & $18 \pm 4$ & $<.01$ \\
Pulmonary artery oxygen saturation (\%) & $69 \pm 13$ & $72 \pm 4$ & NS \\
Mean SAP (mm Hg) & $83 \pm 9$ & $94 \pm 17$ & NS \\
Systemic artery oxygen saturation (\%) & $84 \pm 8$ & $94 \pm 1$ & $<.01$ \\
Vessel diameter (mm) & $3.5 \pm 0.4$ & $3.2 \pm 0.2$ & NS \\
\hline
\end{tabular}

$P A P$, Pulmonary artery pressure; $S A P$, systemic artery pressure; $N S$, not significant.

response to NTG, however, did not differ significantly between the BCPS group and the control group (138\% $\pm 12 \%$ vs $151 \% \pm 20 \%$ ) (Fig 2).

In the BCPS group, the response to $\mathrm{ACH}$ was significantly lower than that to NTG $(P<.05)$, although there was no significant difference in control group.

The relation between the pulmonary flow pulsatility and flow velocity in response to $\mathrm{ACH}$ in the BCPS group. The PI in the BCPS group ranged from 1.1 to 10.5 (median 2.5) and the mean value was $3.7 \pm$ 3.2 , which was significantly lower than that in the control group $(12.0 \pm 5.1 ; P<.01)$. In the BCPS group, the PI was positively correlated with the percent flow velocity response to ACH $(r=0.89, P<.01)$. The pulmonary pulse pressure was also positively correlated with the maximum increase in response to $\mathrm{ACH}(r=$ $0.88, P<.01$ ) (Fig 3). In the response to NTG, there was no correlation with either PI or pulse pressure.

The maximal $\mathrm{ACH}$ percent response to the maximal NTG percent response ratio $(\mathrm{ACH} / \mathrm{NTG}$ response ratio) within each patient was compared between the BCPS and control groups. The ACH/NTG response ratio was significantly lower in the BCPS group (0.89 $\pm 0.09)$ than in control group $(1.06 \pm 0.12)$. The $\mathrm{ACH} / \mathrm{NTG}$ response ratio was positively correlated with the PI $(r=0.87 ; P<.01)$ (Fig 4$)$. 

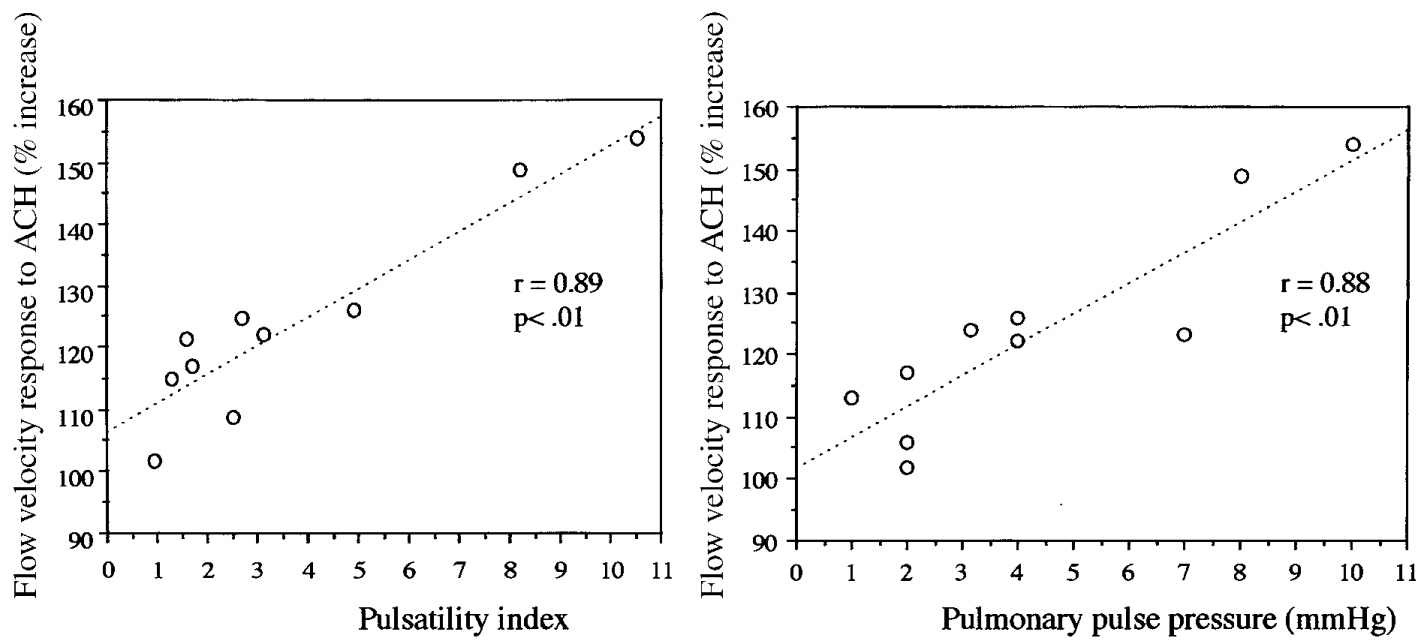

Fig 3. In patients with BCPS, correlation between the flow velocity response to ACH and the PI (left) and the pulmonary pulse pressure (right).

\section{Discussion}

Numerous experimental studies ${ }^{7-10}$ have demonstrated that the endothelium-dependent $\mathrm{ACH}$ response is mainly mediated by NO, because it can be abolished by $N^{\mathrm{g}}$-monomethyl-L-arginine or methylene blue. Also, studies of the human pulmonary artery suggest that an $\mathrm{ACH}-$ mediated response is endothelium-dependent $\mathrm{NO}$ production. ${ }^{11-14} \mathrm{We}$ assessed pulmonary endothelial function using $\mathrm{ACH}$, an endothelium-dependent vasodilator, and compared the effect of $\mathrm{ACH}$ with that of NTG, an endothelium-nondependent vasodilator and exogenous NO donor. Many reports have also shown that the mode of flow plays a major role in modulating pulmonary hemodynamics, particularly vascular resistance, and lung properties such as water content and interstitial hydrostatic pressure ${ }^{5,6,15} \mathrm{It}$ is, therefore, not so surprising that flow pulsatility relates to hemodynamic regulation at the level of endothelial cellular function.

We demonstrated $\mathrm{ACH}$-induced vasorelaxation (endothelium-dependent vasorelaxation) of the conduit pulmonary artery to be significantly attenuated in patients after BCPS, whereas the response to NTG (endothelium-nondependent vasorelaxation) was well preserved. These results suggest endothelial dysfunction and maintained relaxation response of the pulmonary artery smooth muscle in patients undergoing BCPS. Of more importance, the degree of impairment in $\mathrm{ACH}-$ mediated response was positively correlated with pulmonary arterial pulsatility, which depended on the magnitude of supplemental flow in addition to the cavopulmonary flow. The low pulsatility of pulmonary flow may be responsible for abnormal hemodynamic regulation at the endothelial cell level. Our results have clearly supported that patients after BCPS have attenuation of pulmonary endothelial function, for which low pulsatility of cavopulmonary flow is mainly responsible.

Pulmonary vascular response in control subjects. In control children with normal pulmonary hemodynamics, both ACH and NTG stepped up the mean flow velocity to a maximum of more than $150 \%$ of the baseline value for the incremental doses given. This means that the pulmonary vasculature has the potential ability to accept an increase in pulmonary flow. This is, in other words, pulmonary vascular reserve against high pulmonary flow volume. Several reports have demonstrated endothelium producing NO to be important in regulating basal pulmonary artery resistance in healthy human beings, ${ }^{11-13}$ as well as in patients with pulmonary vascular disease. ${ }^{16}$ The maximum ACHinduced increase, therefore, is a quantitative index of pulmonary endothelial function or, more specifically, responsible endothelial NO production.

It remains unclear, however, how much flow velocity increases in response to ACH or to NTG in the normal pulmonary artery. We speculate that the maximum pulmonary vascular reserve in healthy human beings may be more than $200 \%$ of increase. Pulmonary hypertension rarely occurs clinically in patients with atrial septal defect, whose pulmonary/systemic flow ratio is more than 2.0, and in patients undergoing unilateral lobectomy. We studied mainly the NO-dependent vasodilative property in this study; other vasodilative substances such as prostacyclin or endothelium-derived 


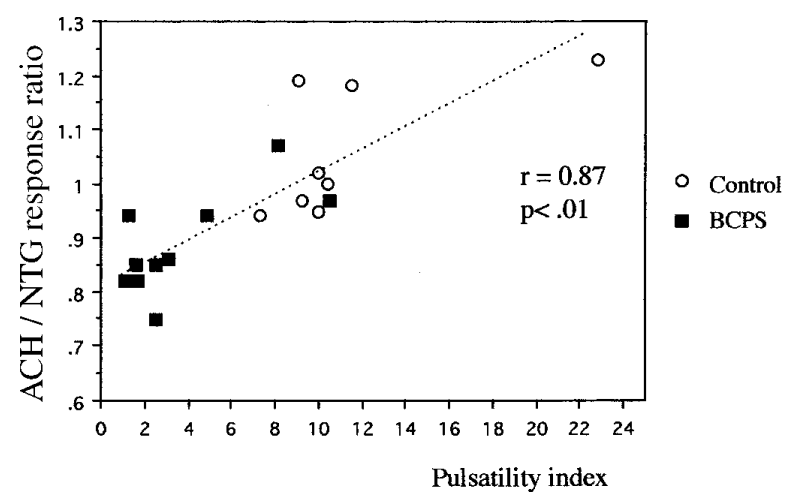

Fig 4. In all subjects, correlation between the maximal $\mathrm{ACH}$ percent response to the maximal NTG percent response ratio and the PI. Open circle, Control group; Closed square, BCPS group.

hyperpolarizing factor may contribute further to the vasodilative response.

Pulmonary vascular response in patients after BCPS. The precise mechanism causing the attenuation of ACH-mediated endothelial response in patients after BCPS must be further explored. Recent in vitro studies have demonstrated that the different flow patterns result in alterations of fluid shear stress and subsequently modulate expression of genes encoding basic fibroblast growth factor, platelet-derived growth factor, ${ }^{17}$ tissue factor, ${ }^{18}$ and synthesis of $\mathrm{NO}^{19}$ in the endothelium. The low pulsatile flow after BCPS resulting in low shear stress may contribute to the attenuation of endothelial NO production. Previous studies ${ }^{20}$ have shown pulsatile flow to be a more powerful stimulus to the release of NO than steady flow, implying that endothelial cells are sensitive to the magnitude of shear stress.

The pulsatility of blood flow may significantly influence both endothelial morphologic characteristics and function through the molecular responses to shear stress. ${ }^{21}$ A recent experimental study ${ }^{22}$ elucidated that the microfilament actin of one of the essential cytoskeletal proteins was redistributed in endothelial cells by shear-induced stimuli. Another study ${ }^{23}$ showed that the $5^{\prime}$ flanking region of endothelial NO synthase contains a cis-acting regulatory sequence identical to the shear-stress responsive element, indicating that shear-stress directly upregulates endothelial NO synthase gene transcription. To the contrary, lessened pulsatile flow pattern, that is, reduced shear stress, may downregulate endothelial NO synthase expression and may attenuate the endothelium-dependent vasodilative response in patients after BCPS.
Systemic arterial oxygen saturation, which may affect the endothelial response, ${ }^{15}$ was significantly lower in patients than in control subjects. These patients have had hypoxia since birth, and oxygen concentration in their bronchial arteries, which supply oxygen to both the pulmonary endothelium and the smooth muscle cells, is lower than that of control subjects. Although we did not observe any connection to arterial oxygen saturation in this study, the hypoxic endothelium may be associated with the attenuation. In addition, the response to NTG tended to be lower, although the difference in response between patients after BCPS and control subjects was not significant. Low oxygen content in the bronchial artery may also mediate attenuation of the effector mechanism in vascular endothelial and smooth muscle cells and, consequently, limit vasorelaxant response.

The vascular endothelium is not only a semipermeable barrier between the blood and interstitium but also a homeostatic organ with physiologic, biologic, and endocrinologic functions. Not only is NO synthesized in the endothelium as a potent vasodilator ${ }^{24}$ but it also reduces platelet aggregation and adhesion, ${ }^{25}$ monocyte-vessel wall interaction, and smooth muscle proliferation, ${ }^{26}$ all of which may impair the ability of the pulmonary vascular endothelium to regulate microcirculation in patients after BCPS.

Study limitations. This study demonstrated the percent increase of mean velocity response to $\mathrm{ACH}$ and NTG but did not calculate the percent increase of flow volume, because vascular diameter was not measured at the end of each drug infusion. Frequent angiography was not performed, because we assumed that frequent contrast infusions would have a deleterious influence on vascular endothelial function, change the vascular reflex, or modify the endothelium-dependent vasorelaxant response. A previous angiographic study has shown that pulmonary artery diameter changed little during $\mathrm{ACH}$ infusion $(1 \% \pm$ $1 \%$ ), that it increased modestly in response to NTG infusion $(5 \% \pm 1 \%)$ in control subjects, and that it changed little during both ACH and NTG infusion in patients with secondary pulmonary hypertension. These observations indicate that the major site of action of each agent is distal to the segmental pulmonary arteries, that is, the downstream resistance vessels. ${ }^{16}$ Our Doppler flow wire method has been validated previously ex vivo and demonstrates excellent linear correlation to volumetric flow with $R^{2}$ values between 0.98 and $1.00 .^{27,28} \mathrm{We}$, therefore, considered average flow velocity analysis to allow accurate assessment of changes in flow volume in this study. 
In the clinical setting, unlike in vitro study, it is difficult to keep blood concentrations of both $\mathrm{ACH}$ and NTG consistent between BCPS and control subjects at the Doppler flow sampling site, because each participant has a different cardiac output and pulmonary flow volume. In addition, it is difficult to calculate the pulmonary flow volume in patients with BCPS having the additional flow. However, there was no difference in the vessel diameter on measurements between the 2 groups, and consistent results were obtained under the wide range of $\mathrm{ACH}$ concentrations.

The patient group is heterogeneous by diagnosis, surgery, and medication. Thus, interference of the different underlying and pre-existing cardiac anatomic abnormalities, of the surgical approach, or of long-term medication may have some influence on endothelial responsiveness. Further, the group that was used as a control group was not completely normal because of pre-existing cardiovascular abnormalities. However, such patients with complex cardiac abnormalities are restricted in number and homogeneity. In addition, we cannot ethically study children without cardiovascular disease.

Finally, we did not study patients without additional pulmonary flow. However, the patients without additional flow should have less pulsatility than our patients. Indeed, in this study, 1 patient with severe pulmonary stenosis, almost pulmonary atresia, had the lowest PI of all.

Clinical implications. The BCPS has become an important staging procedure for the Fontan-type operation in the management of patients with univentricular heart syndrome. Accessory pulmonary blood in BCPS is still controversial. Proponents suggest that a dual source of pulmonary blood flow results in more satisfactory levels of arterial saturation, but opponents emphasize the merits of eliminating volume load to the heart. Our observations suggest that pulmonary flow pulsatility has crucial effects and support the utility of BCPS with additional pulmonary flow from the standpoint of pulmonary endothelial function.

Our data show good flow velocity response to $\mathrm{ACH}$ in 2 patients after BCPS with pulmonary pulse pressure of more than $8 \mathrm{~mm} \mathrm{Hg}$ and PI of more than 8. This favorable response suggests that pulse pressure of more than $8 \mathrm{~mm} \mathrm{Hg}$ for pulsatility is preferable to prevent pulmonary endothelial functional attenuation under BCPS if the ventricular function is stable.

\section{Conclusions}

Endothelium-dependent pulmonary artery relaxation response to $\mathrm{ACH}$ was attenuated in patients after
BCPS, and the degree of attenuation was negatively correlated with the pulmonary flow pulsatility.

Received for publication July 20, 2000; revisions requested Sept 12, 2000; revisions received Sept 26, 2000; accepted for publication Nov 14, 2000.

Address for reprints: Shunji Kurotobi, MD, Department of Pediatrics, Toyonaka Municipal Hospital, 4-14-1, Shibaharacho, Toyonaka City, Osaka, 560-8565, Japan.

\section{REFERENCES}

1. Kobayashi J, Matsuda H, Nakano S, Shimazaki Y, Ikawa S, Mitsuno M, et al. Hemodynamic effects of bidirectional cavopulmonary shunt with pulsatile pulmonary flow. Circulation 1991;84(Suppl):III-219-25.

2. Uemura H, Yagihara T, Kawashima Y, Okada K, Kamiya T, Anderson RH. Use of bidirectional Glenn procedure in the presence of forward flow from the ventricles to the pulmonary arteries. Circulation 1995;92(Suppl):II-228-32.

3. Frommelt MA, Frommelt PC, Berger S, Pelech AN, Lewis DA, Tweddell JS, et al. Does an additional source of pulmonary blood flow alter outcome after a bidirectional cavopulmonary shunt? Circulation 1995;92(Suppl):II-240-4.

4. Mainwarning RD, Lamberti JJ, Uzark K, Spicer RL. Bidirectional Glenn: Is accessory pulmonary blood flow good or bad? Circulation 1995;92(Suppl):II-294-7.

5. Furuse A, Brawley RK, Gott VL. Pulsatile cavopulmonary artery shunt: surgical technique and hemodynamic characteristics. J Thorac Cardiovasc Surg 1972;63:495-500.

6. Richenbacher WE, Pierce WS, Jurmann M, Robins DB, Miller CA, Wise RK, et al. Pulmonary vascular effects of pulsatile and nonpulsatile mechanical right ventricular assistance. Surg Forum 1989;40:254-5.

7. Cooke JP, Stamler J, Andon N, Davies PF, Mckinley G, Loscalzo J. Flow stimulates endothelial cells to release a nitrovasodilator that is potentiated by reduced thiol. Am J Physiol 1990;259:HS04-12.

8. Rees DD, Palmer RMJ, Moncada S. Role of endothelium-derived nitric oxide in the regulation of blood pressure. Proc Natl Acad Sci U S A 1989;86:3375-8.

9. Loeb AL, Longnecker DE. Inhibition of endothelium-derived relaxing factor-dependent circulatory control in intact rats. Am J Physiol 1992;262:H1494-500.

10. Fineman JR, Crowley MR, Heymann MA, Soifer SJ. In vivo attenuation of endothelium-dependent pulmonary vasodilation by methylene blue. J Appl Physiol 1991;71:735-41.

11. Cooper CJ, Landzberg MJ, Anderson TJ, Charbonneau F, Creager MA, Ganz P, et al. Role of nitric oxide in the local regulation of pulmonary vascular resistance in humans. Circulation 1996;93:266-71.

12. Stamler JS, Loh E, Roddy MA, Currie KE, Creager MA. Nitric oxide regulates basal systemic and pulmonary vascular resistance in healthy humans. Circulation 1994;89:2035-40.

13. Celermajer DS, Dollery C, Burch M, Deanfield JE. Role of endothelium in the maintenance of low pulmonary vascular tone in normal children. Circulation 1994;89:2041-4.

14. Katz SD, Schwarz M, Yuen J, LeJemtel TH. Impaired acetylcholine-mediated vasodilation in patients with congestive heart 
failure: role of endothelium-derived vasodilating and vasoconstricting factors. Circulation 1993;88:55-61.

15. Carlin RE, Ferrario L, Boyd JT, Camporesi EM, McGraw DJ, Hakim TS. Determinants of nitric oxide in exhaled gas in the isolated rabbit lung. Am J Respir Crit Care Med 1997;155:922-7.

16. Celermajer DS, Cullen S, Deanfield JE. Impairment of endothelium-dependent pulmonary artery relaxation in children with congenital heart disease and abnormal pulmonary hemodynamics. Circulation 1993;87:440-6.

17. Malek AM, Gibbons GH, Dzau VJ, Izumo S. Fluid shear stress differentially modulates expression of genes encoding basic fibroblast growth factor and platelet-derived growth factor B chain in vascular endothelium. J Cin Invest 1993;92:2013-21.

18. Grabowski EF, Lam FR. Endothelial cell function, including tissue factor expression, under flow conditions. Thromb Haemost 1995;74:123-8

19. Nods M, Morigi M, Donadelli R, Aiello S, Foppolo M, Todeschini M, et al. Nitric oxide synthesis by cultured endothelial cells is modulated by flow conditions. Circ Res 1995;76:536-43.

20. Rubanyi GM, Romero JC, Vanhoutte PM. Flow induced release of endothelium-derived relaxing factor. Am J Physiol 1986;250:H1145-9.

21. Langille BL, Graham JJK, Kim D, Gotlieb AI. Dynamics of shear-induced redistribution of F-actin in endothelial cells in vitro. Arterioscler Thromb 1991;11:1814-20.

22. Marsden PA, Heng HHQ, Scherer SW. Structure and chromosomal localization of the human constitutive endothelial nitric oxide synthase gene. J Biol Chem 1993;268:17478-88.

23. Resnick N, Collins T, Atleison W, Bonthron DT, Dewey CF Jr, Gimbrone MA Jr. Platelet-derived growth factor $\beta$ chain promoter contains a cis-acting fluid shear-stress-responsive element. Proc Natl Acad Sci U S A 1993;90:4591-5.

24. Furchgott RF, Zawadzki JV. The obligatory role of endothelial cells in the relaxation of arterial smooth muscle by acetylcholine. Nature 1980;288:373-6.

25. Ryan US. Pulmonary endothelium: a dynamic interface. Clin Invest Med 1986;9:124-32.

26. Cooke JP, Dzau VJ. Derangement of the nitric oxide synthase pathway, 1-arginine, and cardiovascular disease. Circulation 1997;96:379-82.

27. Doucette JW, Cord PD, Payne HM, Flynn AE, Goto M, Nassi M, et al. Validation of a Doppler guide wire for intravascular measurement of coronary artery flow velocity. Circulation 1992;85:1899-911.

28. Labovitz AJ, Anthonis DM, Cravens TL, Kern MJ. Validation of volumetric flow measurements by means of a Doppler-tipped coronary angioplasty guide wire. Am Heart J 1993;126:1456-61.

\section{Authoritative}

The Journal of Thoracic and Cardiovascular Surgery is the most frequently cited thoracic/cardiovascular surgery journal in the Science Citation Index. An article in JTCVS is sited on average almost twice as often as those in the closest cardiothoracic journal. 